\title{
Jean Bessière (dir.), Littératures francophones et politiques
}

Jean François Plamondon

\section{(2) OpenEdition}

10 Journals

\section{Édition électronique}

URL : http://journals.openedition.org/studifrancesi/6110

DOI : 10.4000/studifrancesi.6110

ISSN : 2421-5856

Éditeur

Rosenberg \& Sellier

\section{Édition imprimée}

Date de publication : 1 mai 2011

Pagination : 217

ISSN : 0039-2944

\section{Référence électronique}

Jean François Plamondon, « Jean Bessière (dir.), Littératures francophones et politiques », Studi Francesi [En ligne], 163 (LV | I) | 2011, mis en ligne le 30 novembre 2015, consulté le 13 janvier 2021. URL : http://journals.openedition.org/studifrancesi/6110 ; DOI : https://doi.org/10.4000/studifrancesi.6110

Ce document a été généré automatiquement le 13 janvier 2021.

\section{(c) (i) (9)}

Studi Francesi è distribuita con Licenza Creative Commons Attribuzione - Non commerciale - Non opere derivate 4.0 Internazionale. 


\title{
Jean Bessière (dir.), Littératures francophones et politiques
}

\author{
Jean François Plamondon
}

\section{RÉFÉRENCE}

JEAN BESSIÈRE (dir.), Littératures francophones et politiques, Paris, Karthala, 2009, pp. 199.

1 Professeur spécialiste des littératures francophones à la Sorbonne, Jean Bessière dirige un collectif d'une grande pertinence, qui met en perspective un certain nombre de problèmes politiques liés aux littératures de langue française issues de la décolonisation. Dans cet ouvrage, on examine la création littéraire dans un dialogue avec la discipline historique qui n'est jamais aussi franchement tranchée qu'on le souhaiterait. Les différentes aires de la grande francophonie sont également analysées par les spécialistes, souvent de grande renommée. Il suffit de penser à BEsSIÈre luimême, à Bernard MOURALIS ou à Jean-François HAMEL pour se convaincre de la qualité des interventions proposées dans cet essai. La fine analyse de Hamel qui travaille sur Hubert Aquin est à la fois complexe et éclairante sur l'œuvre de cet auteur emblématique de la décolonisation québécoise. Selon le professeur de Montréal, engagement et littérature ne vont pas nécessairement de paire pour délivrer les idéaux pourtant appelés de leurs vœux. «Le véritable engagement contraindrait donc la littérature à dire son incapacité à réaliser l'utopie et le politique à se soustraire à l'esthétisation d'une identité maîtresse du monde et du temps» (p. 88). Et les différents niveaux de temps posent aussi problème dans l'ensemble de ces littératures. Ainsi, le temps discursif de l'Histoire et le temps discursif de la littérature semblent en conflit ontologique lorsqu'ils sont de trop près rapprochés, particulièrement dans les Antilles. À tel point que Anne DOUAIRE-BANNY n'hésite pas à affirmer que toute «la question, pour la littérature antillaise, est d'être pénétrée du sentiment de l'Histoire et de la collectivité et de ne pas faire de lecture monumentale, de ne pas en tirer la puissance de cohésion qu'une telle problématique pourtant suscite. C'est que l'Histoire aux 
Antilles, n'en finit pas d'être un vivier de questions, une absence de réponse, donc, toujours, un conflit épistémologique» (p. 105). C'est peut-être aussi pour cette raison que les auteurs antillais ont souvent recours au «réel merveilleux» ou au «réalisme merveilleux» que Dominique CHANCÉ analyse comme deux catégories aux dynamiques inversées. Le premier appelant le merveilleux à se fondre dans le réel pour devenir un sous-ensemble du baroque, et le second intégrant au réalisme sa part de merveilleux. Chancé ne craint pas de rapprocher Chamoiseau de Calvino et de Gadda en signalant que sous la plume de l'auteur martiniquais «s'exerce un léger basculement du réalisme merveilleux créole à la créolité ou à la créolisation comme baroque mondialisé» (p. 121).

2 J'aimerais enfin souligner le très bel article de Bernard MOURALIs intitulé Mongo Beti et l'indépendance. Marchant dans les pas de ce grand intellectuel camerounais, Mouralis fait ressortir toute la complexité de la colonisation et des effets pervers d'une décolonisation qui ne se délivre pas de tous les maux qui venaient avec le régime colonial. Les miroirs gardent souvent en mémoire le reflet du colonisé quand le décolonisé cherche son image. «Mongo Beti souligne ainsi un des caractères essentiels du système colonial: celui-ci a largement inventé de toutes pièces la notion de 'tradition africaine' et a justifié son pouvoir en prétendant restaurer ou conserver cette 'tradition'» (p. 138). Triste le constat de Mouralis qui associe sa voix à celle de Beti dans la mesure où l'on peut se demander à juste titre si une lecture d'un texte africain en langue française par un lecteur d'origine occidentale peut être libérée de tout exotisme. Pouvons-nous lire un texte, libres de toute forme d'idée préconçue? Anne DouaireBanny, reprenant les propos de Jean Bessière se posait d'ailleurs une question un peu similaire: «n'y a-t-il pas une difficulté à penser une réalité non-occidentale, et qui se veut telle, ou que l'on veut penser telle, avec des outils occidentaux?» (p. 101). 